\title{
CASE REPORT \\ The unsuspected killer: Liquefied petroleum gas overexposure in South Africa
}

\author{
L W J Sampson; ${ }^{1}$ N van der Schyff, ${ }^{2}$ MB ChB, MPhil Emerg Med, FCP (SA); C Cupido, ${ }^{2}$ MB ChB, FCP (SA) \\ ${ }^{1}$ Sixth-year medical student, Faculty of Health Sciences, University of Cape Town, South Africa \\ ${ }^{2}$ Department of Internal Medicine, Victoria Hospital, Wynberg, Cape Town, South Africa
}

Corresponding author: L Sampson (sampson.mbchb@gmail.com)

\begin{abstract}
A 21-year-old woman with no past medical history of note was found unconscious together with five of her family members after prolonged exposure to liquefied petroleum gas. She was admitted to the intensive care unit at Victoria Hospital, Wynberg, Cape Town, South Africa, following resuscitation for pulseless electrical activity. On examination the following was found: coma without focal neurology; shock requiring fluid resuscitation and adrenaline; probable pneumonitis or aspiration pneumonia; acute rhabdomyolysis with severe metabolic acidosis; and raised serum $\mathrm{K}^{+}$. A carboxyhaemoglobin test was unable to confirm or exclude carbon monoxide poisoning.
\end{abstract}

S Afr Med J 2015;105(2):152. DOI:10.7196/SAMJ.9267

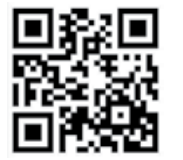

Liquefied petroleum gas (LPG) contains propane and butane gas and is generally used as an alternative to electricity for cooking and heating. Because of increasing energy costs, it is now more commonly used in South Africa (SA). ${ }^{[1]}$ Although it is a cheaper source of energy, there are specific health risks to the uninformed user.

In SA, LPG is sold in pressurised, sealed canisters, and includes a warning/instruction leaflet from the South African Bureau of Standards, requiring that all LPG systems be installed by a professional. ${ }^{[2]}$ The gas is odourless and colourless, but an odourant is added to the container before sale. ${ }^{[3]}$

Besides being highly flammable, the gas can create a hypoxic environment by consuming atmospheric oxygen $\left(\mathrm{O}_{2}\right)$ (especially in small enclosures) to form carbon monoxide (CO), which is toxic; therefore, when used there must be adequate ventilation and no leakages. LPG is also a simple asphyxiant with anaesthetic properties. However, the gas itself is non-toxic. ${ }^{[2,3]}$

A literature search found only two cases of LPG overexposure, with resultant rhabdomyolysis.

\section{Case report}

The first objective in the management of our patient was to identify the insulting agent by means of a collateral history from her boyfriend and the emergency services personnel - the latter reported a 'musty' smell and found an open gas canister in her kitchen.

CO poisoning could not be excluded because of laboratory and transit errors, preventing a carboxyhaemoglobin level from being obtained. However, after consulting the literature, we confirmed LPG overexposure as the likely cause because of the following:

- the collateral history indicated the gas as the possible agent

- the patient had a reduced level of consciousness and signs of a probable pneumonitis - both fitting the effects commonly associated with overexposure to LPG.

Furthermore, significant rhabdomyolysis was present; it is, however, a rare presentation in cases of LPG overexposure. ${ }^{[4,5]}$ This was coupled with pulseless electrical activity, which is related to rhabdomyolysis.
In our patient it was caused by hypoxia, severe metabolic acidosis, hyperkalaemia and long-term immobility.

After resuscitation, which included the administration of $100 \%$ oxygen and adrenaline, the patient's electrocardiogram was normal, which is rather unusual in the light of the hyperkalaemia. Although adrenaline is contraindicated in the management of a patient presenting with overexposure to LPG, as it causes tachyarrhythmias, ${ }^{[6]}$ in this case it may have been protective as adrenaline reduces serum potassium levels. ${ }^{[7]}$

Further management in this case was supportive, maintaining ventilation and renal function.

With increased use of LPG in SA and the lack of end-user education regarding risks and correct installation, LPG overexposure could become a likely and unnecessary contributor to morbidity and mortality in SA. The points taken from our case are that a collateral history is important, removal from the compromised environment is the first step in management, and CO poisoning should be excluded where possible. Initial hospital management is resuscitation, $100 \%$ oxygen and monitoring of renal function and fluid status.

Although a rare presentation, rhabdomyolysis should always be excluded, and special attention given to serum $\mathrm{K}^{+}$levels. As was seen in our patient, adrenaline inadvertently aided treatment, but management of hyperkalaemia should be by more conventional methods such as intravenous insulin and glucose, furosemide, chelation and inhaled salbutamol with $100 \%$ oxygen, depending on the level of hyperkalaemia.

Patients should be educated regarding the possible dangers of LPG use before discharge from hospital.

\footnotetext{
References

1. Mohlakoana N, Annecke W. Finally breaking the barriers: South African case study on LPG use by lowincome urban households. http://www.hsrc.ac.za/en/research-outputs/view/3951 (accessed 17 July 2013). income urban households. http://www.hsrc.ac.za/en/research-outputs/view/3951 (accessed 17 July 2013).
South African Bureau of Standards (SABS). The Handling, Storage, Distribution and Maintenance of 2. South African Bureau of Standards (SABS). The Handling, Storage, Distrib
Liquefied Petroleum. SANS 10087-2:2011. 3rd ed. Pretoria: SABS, 2011:20.

3. AFROX. Material safety and data sheet (MSDS) liquefied petroleum gas \& propane. http://www.afrox.co.za/ internet.global.corp.zaf/en/images/LiquefiedPetroleumGas_Propane266_27684.pdf (accessed 17 July 2013). . Prasad S, Singh R, Manocha R, et al. Acute massive rhabdomyolysis due to inhalation of LPG. Journal of the Association of the Physicians of India 2009;57:472-473.

5rangides CY, Tzortzatos GV, Koulouras V, Pneumatikos IA. Acute massive rhabdomyolysis due to prolonged inhalation of liquid gas. Eur J Emerg Med 2003;10(1):44-46.

6. Safety Data Sheet for Liquefied Petroleum Gas (LPGas). http://www.unigas.com.au/downloads/Safety Data_Sheet_for_LPG_Jan_2011.pdf (accessed 17 July 2013).

7. Editorial. Adrenaline and potassium: Everything in flux. Lancet 1983;322(8364):1401-1403.
} 